\title{
Hair Mercury Levels in Periodontal Patients in Comparison with Healthy Individuals
}

\author{
${ }^{1}$ Hamidreza Hasanjani Roushan, ${ }^{2}$ Hadi Parsian, ${ }^{3}$ Ramin Alijannia, ${ }^{4}$ Abbas Mosapour, ${ }^{5}$ Soraya Khafri
}

\begin{abstract}
Introduction: The clinical manifestation of periodontal diseases (such as gingivitis and chronic periodontitis) results from a complex interplay between the etiologic agents such as bacteria that present in the dental plaque, genetic factors, systemic diseases, smoking and exposure of some heavy metals, such as mercury. In this study, we aimed to evaluate hair mercury levels in healthy subjects in comparison with periodontal patients.
\end{abstract}

Materials and methods: One hundred twenty subjects were enrolled in this study. The included persons were divided into 3 groups: healthy subjects $(n=40)$, gingivitis $(n=40)$ and chronic periodontitis patients $(n=40)$. Hair samples were collected from occipital area of head. Total mercury levels were determined by atomic absorption spectrophotometry.

Results: The difference between mercury levels in three groups were statistically significant ( $p$-value $<0.001)$. Mercury level in periodontitis patients was greater than the gingivitis group ( $p$-value < 0.001). In addition the differences between mercury levels in periodontitis patients $v s$ healthy individuals was significant $(p$-value $=0.048)$. The gingivitis patients had lower levels of mercury than the control group, but the difference was not significant ( $p$-value $=0.170)$.

Conclusion: The results showed that the levels of mercury are to some extent differed in periodontal diseases in comparison with the healthy individuals. A study with larger sample size is needed for clarification of this issue.

Keywords: Chronic periodontitis, Gingivitis, Mercury.

How to cite this article: Roushan $\mathrm{HH}$, Parsian $\mathrm{H}$, Alijannia R, Mosapour A, Khafri S. Hair Mercury Levels in Periodontal Patients in Comparison with Healthy Individuals. World J Dent 2014;5(3):166-169.

Source of support: Nil

Conflict of interest: None

1,2,5Assistant Professor, ${ }^{3}$ Dentistry Student

${ }^{4} \mathrm{MSc}$ in Clinical Biochemistry

${ }^{1,3}$ Department of Periodontology, Dental Faculty, Dental Materials Research Center, Babol University of Medical Sciences, Babol, Iran

${ }^{2}$ Department of Biochemistry and Biophysics, Social Determinants of Health Research Centre, Babol University of Medical Sciences, Babol, Iran

${ }^{4}$ Department of Biochemistry and Biophysics, Faculty of Medicine, Babol University of Medical Sciences, Babol, Iran

${ }^{5}$ Department of Social Medicine, School of Medicine, Babol University of Medical Sciences, Babol, Iran

Corresponding Author: Hadi Parsian, Assistant Professor Department of Biochemistry and Biophysics, Social Determinants of Health Research Centre, Babol University of Medical Sciences, Ganjafrooz Ave, Babol, Iran, Phone: +98-1112190569 Fax: +98-1112190569, e-mail: hadiparsian@yahoo.com

\section{INTRODUCTION}

Periodontitis is an inflammatory diseases that affecting the periodontium. Loss of the alveolar bone, loosening and loss of teeth are the major problems that accompanying in this disease. This disease is classified to the following major categories, i.e. gingivitis, chronic periodontitis, aggressive periodontitis, periodontitis as a manifestation of systemic disease, necrotizing ulcerative gingivitis/periodontitis, abscesses of the periodontium and combined periodonticendodontic lesions. ${ }^{1}$

There are various factors that are related to the etiology of this disease. It is proposed that poor or ineffective oral hygiene is located in the first line. This leads to the formation of dental plaque that is consisted of mycotic and bacterial matrix. Malnutrition, some systematic diseases, such as diabetes and smoking are the other important causes of periodontitis. $^{2-12}$

There are evidences that heavy metal exposure, such as mercury and its derivatives are connected to the oral health conditions and diseases. ${ }^{12}$ Today the most widespread exposures to mercury are from three ways: Mercury vapor, methylmercury in sea foods and ethylmercury in the form of thimerosal used as a preservative in vaccines. ${ }^{13}$ After exposure to the mercury and its derivatives, such as methylmercury, bulk of them accumulates in human hair. ${ }^{14}$ Contamination of sea foods to mercury is a major route of mercury entrance to human body. In addition, there are other ways in which mercury can enter to the body. Use of amalgam as a dental restorative material, in which mercury is one of the important constituents, is another route.

In this case control study, we aimed to determine the levels of human hair contamination with mercury in periodontitis patients. To end this, we measured the hair levels of mercury in healthy individuals in comparison of periodontitis patients.

\section{MATERIALS AND METHODS}

\section{Study Population}

One hundred twenty subjects were participated in this study. The subjects were selected among outpatients that referred to the Periodontics Department of Dentistry Faculty in Babol University of Medical Sciences. Subjects were classified into 
3 groups: Group A was the healthy individuals without any sign of periodental diseases. Group B was the persons with gingivitis and group $\mathrm{C}$ consisted of chronic periodontitis patients. Diagnosis of gingivitis and chronic periodontitis were done according to the standard criteria as follow:

- Gingivitis: Bleeding from the gingival sulcus on gentle probing and color change of gingiva from pink to red or bluish red color and a ginigival index $<1$.

- Chronic periodontitis: Pocket formation that was deeper than $4 \mathrm{~mm}$ with clinical attachment loss that was greater than $2 \mathrm{~mm} .{ }^{15}$

Each person with a history of cigarette smoking, systemic disorders (such as diabetes, rheumatoid arthritis, genetic disorders, psychosocial disorders and cardiovascular disease) and any history of periodontal treatment during the last 6 months were excluded.

\section{Hair Sampling and Analyses}

After receiving the written consent from each person, hair strands from the root were taken from the occipital area of head with stainless steel tweezer. Hair were placed into a capped tube and sent to the biochemistry and biophysics department of medicine faculty.

\section{Digestion Procedure}

For measurement of total mercury in human hair, sample preparation and digestion were conducted as reported in previous works with some modification. ${ }^{16}$ The hair samples were cut in very small pieces and ultrasonically (Bandelin Sonopuls, Germany) washed in a $0.1 \%$ Triton X-100 solution for $20 \mathrm{~mm}$ in department of biochemistry and biophysics. After rinsing the samples with deionized water, hair samples were rinsed with acetone and air-dried. Nearly $40 \mathrm{mg}$ of the dried hair was placed in a $5 \mathrm{ml}$ test tube and $700 \mu \mathrm{l}$ of $\mathrm{HNO}_{3}$ $(5 \mathrm{M})$ was added to the samples. Then tubes were heated at $100^{\circ} \mathrm{C}$ for 120 minutes. Digested samples were stored and protected from light, at $4^{\circ} \mathrm{C}$ for next procedure.

\section{Extraction Procedure}

After cooling down the digested samples, $4 \mathrm{ml}$ of $\mathrm{NaOH} 1 \mathrm{M}$ and $1 \mathrm{ml}$ of acetate buffer solution were added to the sample in order to obtain a $\mathrm{pH}$ of 4.5. $200 \mu \mathrm{l}$ of the $1 \%$ ammonium pyrrolidine dithiocarbamate (APDC) solution and $500 \mu \mathrm{l}$ of methyl-isobutylketone (MIBK) were the other materials that added to the samples. Samples were vigorously mixed and centrifuged at 2700 RPM for 20 minutes. Finally, a $20 \mu 1$ of the supernatant organic phase containing the Hg-APDC complex was directly introduced into a graphite tube of atomic absorption spectrophotometry (AAS) and atomized. ${ }^{16}$

\section{Analysis of the Mercury Levels by AAS}

PG990 atomic absorption spectrophotometer equipped with graphite furnace was used for measurement of hair mercury levels. The operating parameters were set as recommended by manufacturer. A stock standard solution of mercury $(\mathrm{Hg})$ at a concentration of $1000 \mathrm{mg} / \mathrm{l}(\mathrm{ppm})$ was used for drawing the standard curve. The calibration curve was established using the following working standards solutions: $0,7.81$, $15.62,31.25$ and $62.50 \mu \mathrm{g} / 1$ (ppb). The thermal cycle of the AAS program for measurement of hair mercury levels are presented in Table 1.

\section{Statistical Analysis}

Results of the numerical variables are presents as mean $\pm \mathrm{SD}$. A p-value less than 0.05 (two tailed) considered significant. For comparison of various numerical variables, we used from ANOVA test, Scheffe post hoc model. All statistical analysis was done by commercially available program of SPSS version 18 .

\section{RESULTS}

In this study, 120 subjects were enrolled and classified into 3 groups: healthy subjects, gingivitis patients and chronic periodontitis patients. Characteristics of the included persons are presented in Table 2 . In addition in this table hair mercury levels in included persons are also presented. As we observe in this table, chronic periodontitis patients had the highest levels of mercury levels in their hair, but the gingivitis patients had the lowest level of mercury. For comparison of mercury levels in our included groups, simultaneously,

Table 1: Atomic absorption spectrophotometry working condition for total mercury determination

\begin{tabular}{lllll}
\hline Step & $\begin{array}{l}\text { Temperature } \\
\left({ }^{\circ} \mathrm{C}\right)\end{array}$ & $\begin{array}{l}\text { Ramp } \\
\left({ }^{\circ} \mathrm{C} / \mathrm{S}\right)\end{array}$ & $\begin{array}{l}\text { Hold } \\
\text { time }\end{array}$ & $\begin{array}{l}\text { Argon flow } \\
\text { rate }(\mathrm{ml} / \mathrm{min})\end{array}$ \\
\hline Drying & 120 & 205 & 15 & 300 \\
Pyrolysis & 250 & 15 & 20 & 300 \\
Atomization & 1600 & 1 & 4 & Off \\
Cleaning & 2000 & 1 & 2 & 300 \\
\hline
\end{tabular}

Table 2: Characteristics of the included persons in study

\begin{tabular}{llll}
\hline $\begin{array}{l}\text { Disease/ } \\
\text { variables }\end{array}$ & $\begin{array}{l}\text { Healthy } \\
\text { persons }\end{array}$ & $\begin{array}{l}\text { Gingivitis } \\
\text { patients }\end{array}$ & $\begin{array}{l}\text { Chronic } \\
\text { periodontitis } \\
\text { patients }\end{array}$ \\
\hline Age (years) & 25.5 & 31.2 & 41.1 \\
$\mathrm{BMI}\left(\mathrm{kg} / \mathrm{m}^{2}\right)$ & 23.9 & 25.1 & 27.6 \\
$\mathrm{CAL}(\mathrm{mm})$ & - & - & $>2$ \\
$\mathrm{Gl}$ & $<1$ & $>1$ & - \\
$\begin{array}{l}\text { Mercury levels } \\
\text { (ppb) }\end{array}$ & $12.7 \pm 8.0$ & $9.5 \pm 5.1$ & $16.9 \pm 8.5$
\end{tabular}

BMI: Body mass index; CAL: Clinical attachment loss; GI: Gingival index 
Table 3: Mercury levels in included persons according to the Age and BMI subclassification

\begin{tabular}{|c|c|c|c|c|c|c|c|c|}
\hline \multirow{2}{*}{$\begin{array}{l}\text { Disease/ } \\
\text { variable }\end{array}$} & \multicolumn{3}{|c|}{ Age subclassification } & \multirow[t]{2}{*}{$p$-value } & \multicolumn{3}{|c|}{ BMI subclassification } & \multirow[t]{2}{*}{$p$-value } \\
\hline & $<30$ & $30-40$ & $>40$ & & $19-25$ & $25-30$ & $>30$ & \\
\hline $\begin{array}{l}\text { Healthy } \\
\text { persons }\end{array}$ & $12.65 \pm 7.7$ & $13.70 \pm 10.9$ & *- & 0.791 & $11.28 \pm 7.6$ & $16.93 \pm 7.9$ & $12.05 \pm 8.5$ & 0.323 \\
\hline $\begin{array}{l}\text { Gingivitis } \\
\text { patients }\end{array}$ & $9.15 \pm 5.5$ & $9.38 \pm 4.0$ & $12.27 \pm 6.8$ & 0.552 & $8.6 \pm 4.3$ & $11.6 \pm 6.1$ & $6.46 \pm 3.5$ & 0.134 \\
\hline $\begin{array}{l}\text { Chronic } \\
\text { periodontitis } \\
\text { patients }\end{array}$ & $10.50 \pm 5.9$ & $17.21 \pm 7.5$ & $17.41 \pm 9.5$ & 0.560 & $17.14 \pm 10.4$ & $17.80 \pm 7.8$ & $14.42 \pm 9.1$ & 0.641 \\
\hline$p$-value & 0.206 & 0.018 & 0.321 & - & 0.016 & 0.052 & 0.397 & 一 \\
\hline
\end{tabular}

*There was no person in this age category

ANOVA test were used. The differences in the mercury levels in three groups were statistically significant $(\mathrm{p}<0.001)$. The differences between mercury levels in healthy person's vs gingivitis patients were not significant ( $\mathrm{p}$-value $=0.170$ ), but with periodontitis patients were significant ( $\mathrm{p}$-value $=$ 0.048). In addition we observed that, the differences between mercury levels in gingivitis patients $v s$ periodontitis patients were significant ( $\mathrm{p}$-value $<0.001$ ).

For evaluation of the probable impact of age and BMI on the levels of mercury, we subclassified the age and BMI variables as follow:

Age: Age $<30,30-40$ and $>40$ years old. $\mathrm{kg} / \mathrm{m}^{2}$.

BMI: $19<\mathrm{BMI}<25,25<\mathrm{BMI}<30$ and $\mathrm{BMI}>30$

The mercury levels in these subclassification groups are presented in Table 3. Chronic periodontitis patients with lower than 30 years old, had lower mercury levels and patients with greater than 40 years old, had the highest hair mercury levels. Again the levels of mercury in gingivitis patients were the lowest, but with increasing the age an increase in the levels of mercury were observed. Such trends were observed in chronic periodentitis patients and also healthy individuals. Our finding related to the impact of various BMI classes on hair mercury levels are also presented in this table. It seems that the impact of BMI on hair mercury levels is not in a definite trend.

\section{DISCUSSION}

For analysis of the levels of mercury in human body, several indicators such as blood, ${ }^{17}$ urine and hair ${ }^{18}$ were introduced. It is proved that hair is a suitable tissue for indication of human exposure to mercury. ${ }^{16}$ In this study we used from subjects hair as a source of probable contamination with mercury. The determination of mercury in hair is a time consuming procedure but a precise method. For analysis of total mercury in hair, digestion with $\mathrm{HNO}_{3}$ instead of $\mathrm{HCl}$ or $\mathrm{H}_{2} \mathrm{SO}_{4}$ is preferred. ${ }^{16}$ In addition for detection of the mercury levels we used graphite furnace atomic absorption spectrophotometry that is a powerful tool that able to detect the levels of elements in ppb scale.

According to the result of the present study, chronic periodontitis patients had the highest level of mercury in comparison with the gingivitis and healthy individuals. As previously mentioned it, exposure to mercury in form of inhalation or by foods especially sea foods, are known as one of the risk factors of oral and mouth diseases. In our study population, the levels of mercury were not in toxic range, ${ }^{19}$ but chronic periodontitis patients had the highest mercury levels. In addition there is a hypothesis that stated with increasing in the age, there is a gradual increase in human mercury levels. ${ }^{20}$ In the present study, data showed that subjects with higher age had higher hair mercury levels in all groups. This emphasizes that with aging an increase in hair mercury levels occurs.

For evaluation of the probable impact of BMI on the levels of mercury, analysis of the hair mercury levels, according to the BMI subclassification were performed. ${ }^{21}$ We observed that persons in BMI of 19 to $25 \mathrm{~kg} / \mathrm{m}^{2}$ had a statistically significant difference in their hair mercury levels and again the chronic periodontitis patients had the highest level.

The reported studies regarding to the hair mercury levels in oral and mouth problems is very low. In a study that carried out by Han et al on 598 males and 730 females in Korea, researchers showed that mercury exposure is associated with periodontitis (odds ratio $=3.17$ ) and males had higher probability of having periodontitis than females. ${ }^{19}$ Dental health of 73 workers previously exposed to mercury vapor was compared with 51 nonexposed individuals by Holland et al. Researchers did not find a correlation between mercury exposure and periodontal disease and reported no significant difference between the exposed workers and the referents. ${ }^{22}$ Kim et al in 2013 studied the levels of mercury in blood (but not hair) of periodontitis patients. They observed that association between blood mercury levels and periodontitis was significant in the Korean male population. ${ }^{23}$ 
Various mechanisms are proposed for possible role of mercury in creating the oral and mouth problems. It seems that after mercury exposure, impairment of lymphocyte proliferation, cytogenetic damage and incidence of acute and chronic inflammation are the major probable mechanisms. ${ }^{24}$

This study had some limitations. First of all, the patients were not matched according to the number of filled teeth with amalgam. According to the evidence-based analysis, an amalgam restoration is safe $\mathrm{e}^{25}$ and some studies did not find a correlation between hair mercury levels with number of dental amalgam fillings. ${ }^{26}$ In addition it was better that the subjects matched according to their diet, because one of the other major route of mercury entrance to the body is foods especially sea foods. It seems that another study with the mentioned criteria's is needed to reach to an exact conclusive statement for the potential role of mercury as a periodontitis inducing agent in our population.

\section{CONCLUSION}

It seems that the level of hair mercury levels in chronic periodentitis patients is higher than the healthy individuals. It is needed to more comprehensive study for reaching to an exact conclusive statement for the potential role of mercury as a periodontitis inducing agent in our population.

\section{ACKNOWLEDGMENTS}

This study was supported by a grant from Babol University of Medical Sciences. We greatly thanks from the staff of Biochemistry and Biophysics Department, Faculty of Medicine and Periodontics Department of Dentistry Faculty for their help.

\section{REFERENCES}

1. ArmitageGC.Developmentofaclassification system forperiodontal diseases and conditions. Ann Periodontol 1999 Dec;4(1): $1-6$.

2. Aubrey C. Blastomycosis of the gingiva and jaw. Can Med Assoc J 1932;26(6):662-665.

3. Urzúa B, Hermosilla G, Gamonal J. Yeast diversity in the oral microbiota of subjects with periodontitis: Candida albicans and Candida dubliniensis colonize the periodontal pockets. Med Mycol 2008 Dec;46(8):783-793.

4. Matsuo T, Nakagawa H. Endogenous Aspergillus endophthalmitis associated with periodontitis. Ophthalmologica 1995;209(2): 109-111.

5. Migliari D, Sugaya N. Periodontal aspects of the juvenile form of paracoccidioidomycosis. Revista do Instituto1998 JanFeb;40(1):15-18.

6. Lalla E, Cheng B, Lal S. Diabetes mellitus promotes periodontal destruction in children. J Clin Periodont 2007 Apr;34(4): 294-298.
7. Patrick O, Bercy P. Effects of smoking on periodontal health. Advances in Therapy 2000 Sep-Oct;17(5):230-237.

8. Tomar S, Asma S. Smoking-attributable periodontitis in the United States. J Periodont 2000 May;71(5):743-751.

9. Ryder MI. The influence of smoking on host responses in periodontal infections. Periodont 2000, 2007;43(1):267-277.

10. Pauletto NC, Liede K, Nieminen A. Effect of cigarette smoking on oral elastase activity in adult periodontitis patients. $\mathrm{J}$ Periodont 2000 Jan;71(1):58-62.

11. Persson L, Bergström J, Gustafsson A. Effect of tobacco smoking on neutrophil activity following periodontal surgery. J Periodont 2003 Oct; 74(10):1475-1482.

12. Clarkson TW. The three modern faces of mercury. Environ Health Perspect 2002 Feb;110(Suppl 1):11-23.

13. Peruzzo DC, Benatti BB, Glaucia A. A systematic review of stress and psychological factors as possible risk factors for periodontal disease. J Periodont 2007 Aug;78(8):1491-1504.

14. Thomas W, Jayesh B, Nazzareno B. Mechanisms of Mercury Disposition in the Body. Am J Industrial Med 2007Oct; 50(10):757-764.

15. Newman MG, Takei HH, Carranza FA. Clinical periodontology. 9th ed. WB Saunders Co. 2006; Chap 4:64-65.

16. Montuori P, Jover P, Pagano A. Improvement on a total mercury determination method in human hair by using GF-AAS detection. J Prev Med Hyg 2007;48:43-46.

17. Akagi H, Malm O, Branches FJP, Kinjo Y, Kashima Y. Human exposure to mercury due to goldmining in the Tapajos River Basin, Amazon, Brazil: speciation of mercury in human hair, blood and urine. Water, Air Soil Poll 1995;80:85-94.

18. Randjean P, White RF, Weihe P, Jorgensen PJ. Neurotoxic risk caused by stable and variable exposure to methyl mercury from seafood. Ambul Pediatr 2003 Jan-Feb;3(1):18-23.

19. Han D, Lim S, Sun B. Mercury exposure and periodontitis among a Korean population. J Periodontal $2009 \backslash$ Dec;80(12):1928-1936.

20. Laura G. Methylmercury contamination in fish and shellfish. CSA Discovery Guides 2007;1:1-9.

21. Chang HY, Kim BG. Relationship between blood mercury concentration and waist-to-hip ratio in elderly Korean individuals living in Coastal areas. J Preventive Med Public Health 2011 Sep;44(5):218-225.

22. Holland RI, Ellingsen DG, Olstad ML, Kjuus H. Dental health in workers previously exposed to mercury vapour at a chloralkali plant. Occupational and Environmental Med 1994 Oct;51(10): 656-659.

23. Kim Y, Lee BK. Association between blood lead and mercury levels and periodontitis in the Korean general population: Analysis of the 2008-2009 Korean National Health and Nutrition Examination Survey data. Int Archives Occupational and Environmental Health 2013 July;86(5):607-613.

24. Marucia I, Amorim M. Cytogenetic damage related to low levels of methylmercury contamination in the brazilianamazon. An Acad Bras 2000 Dec;72(4):496-507.

25. Dodes JE. The amalgam controversy. An evidence-based analysis. J Am Dent Assoc 2001 Mar;132(3):348-356.

26. Batista J, Schuhmacher M, Domingo JL, Corbella J. Mercury in hair for a child population from Tarragona Province, Spain. Sci Total Environ 1996 Dec 20;193(2):143-148. 